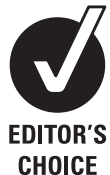

${ }^{1}$ Institute of Psychiatry, King's College London, London, UK ${ }^{2}$ Departamento de Psiquiatría, Universidad de Antioquia, Antioquia, Colombia ${ }^{3}$ Division of Psychology and Language Sciences, University College London, London, UK

${ }^{4}$ School of Psychology, Cardiff University, Cardiff, UK

\section{Correspondence to} Dr 0 Deeley, Institute of Psychiatry, King's College London, Box P050, De Crespigny Park, London SE5 8AF, UK; peter.q.deeley@kcl.ac.uk

Received 2 November 2009 Revised 17 August 2010 Accepted 18 August 2010 Published Online First 30 September 2010

\title{
Dissociation in hysteria and hypnosis: evidence from cognitive neuroscience
}

\author{
Vaughan Bell, ${ }^{1,2}$ David A Oakley, ${ }^{3,4}$ Peter W Halligan, ${ }^{4}$ Quinton Deeley ${ }^{1}$
}

\begin{abstract}
Jean-Martin Charcot proposed the radical hypothesis that similar brain processes were responsible for the unexplained neurological symptoms of 'hysteria', now typically diagnosed as 'conversion disorder' or 'dissociative (conversion) disorder', and the temporary effects of hypnosis. While this idea has been largely ignored, recent cognitive neuroscience studies indicate that (i) hypnotisability traits are associated with a tendency to develop dissociative symptoms in the sensorimotor domain; (ii) dissociative symptoms can be modelled with suggestions in highly hypnotisable subjects; and (iii) hypnotic phenomena engage brain processes similar to those seen in patients with symptoms of hysteria. One clear theme to emerge from the findings is that 'symptom' presentation, whether clinically diagnosed or simulated using hypnosis, is associated with increases in prefrontal cortex activity suggesting that intervention by the executive system in both automatic and voluntary cognitive processing is common to both hysteria and hypnosis. Nevertheless, while the recent literature provides some compelling leads into the understanding of these phenomena, the field still lacks well controlled systematically designed studies to give a clear insight into the neurocognitive processes underlying dissociation in both hysteria and hypnosis. The aim of this review is to provide an agenda for future research.
\end{abstract}

\section{INTRODUCTION}

At the close of the 19th century, the French neurologist Jean-Martin Charcot proposed the radical hypothesis that similar brain processes were responsible for the unexplained neurological symptoms of hysteria and the pseudo-neurological behaviours commonly produced by hypnosis. This hypothesis stemmed from many years of work in which hypnosis was used to produce or resolve symptoms in patients with hysteria, including post-traumatic cases. ${ }^{1}$ Even in a modern context, Kirsch $^{2}$ notes that "Hypnotised subjects are asked to experience paralysis, amnesia, anaesthesia, involuntary movements and hallucinations. In fact, hypnotisability is measured as the number of conversion and dissociation symptoms that the person is able to display. ${ }^{2}$ Central to Charcot's explanation was the concept that symptoms could derive from unconscious 'fixed' ideas based on suggestions or autosuggestions "remaining isolated from the rest of the mind and expressing themselves outwardly through corresponding motor phenomena" (quoted in Ellenberger ${ }^{1}$ ). Recent advances in cognitive neuroscience provide an opportunity to evaluate Charcot's hypothesis.
This review focuses on 'hysteria' which classically describes the presentation of medical symptoms without evidence of tissue pathology that can adequately explain the impairment, and its relationship to the effects of hypnosis. While the concept of hysteria has historically varied, ${ }^{3}$ this review focuses on aspects of the condition which have been modelled using hypnosis; to date, these typically include conditions that would be diagnosed as conversion disorder and affect voluntary motor or sensory function, or would be diagnosed as psychogenic, functional or dissociative amnesia.

These remain controversial and curious diagnoses characterised by putative psychological mechanisms rather than any specific symptom or pathognomonic finding. The review begins by considering the historical links between the two proposed psychological constructs implicated in hysteria-namely 'dissociation' and 'conversion'before examining the parallels between hysteria and hypnosis.

\section{DISSOCIATION AND CONVERSION}

Although not the first to use the term, the philosopher and psychiatrist Pierre Janet wrote extensively about dissociation, and it is Janet's conception of dissociation as a 'narrowing of the field of consciousness' resulting in the compartmentalisation of normally integrated mental functions that continues to define the condition today. ${ }^{1}$ Janet cited unresolved traumatic memories as the cause of fixed ideas and of dissociation in hysteria, and felt a tendency to dissociate was an innately pathological process whichever form it took. Freud, who had studied with Charcot, extended Janet's ideas in Studies in hysteria (co-authored with Joseph Breuer) by proposing that the dissociative process resulted from the repression of traumatic material into the unconscious, much of which related to sexual memories or desires. Thus following Freud, hysteria became 'conversion hysteria', ${ }^{1}$ typically understood as a psychological defence mechanism that converts emotional distress associated with repressed memories of trauma into physical symptoms, so producing dissociation.

Nevertheless, it is not clear whether the concept of conversion is testable given the circular definition whereby patients with conversion symptoms are unable to describe precipitating traumata owing to the events being repressed into the unconscious, while the absence of remembered trauma is used as evidence for this process at work. ${ }^{3}$ The Freudian notion of 'conversion' as a defence against pathological emotional states is also suspect in light of the fact that in patients with diagnoses of 
hysteria-like conditions, psychiatric comorbidity is the norm rather than the exception. ${ }^{4}$

Moreover, almost all of the available evidence that can be reviewed concerns the clinically presented 'end states' (ie, symptoms) of hysteria, and does not address the processes that led up to them or indeed to the possibility that there is a 'state' of hysteria that can be identified over and above the presence of specific symptoms. Indeed, relatively little research has looked specifically at causal neuropsychology, with a single case study by Kanaan and colleagues 5 and a group study by Voon and colleagues ${ }^{6}$ being the only prominent examples. In light of this, the view adopted here is that the symptoms of hysteria (paralyses, amnesias, sensory losses and so on) are examples of a form of dissociation (compartmentalisation) in which relatively circumscribed aspects of cognition become separated from normal subjective awareness or voluntary control. ${ }^{7}$ Further, these dissociative 'end states' can be viewed as distinct from 'conversion' as a hypothetical process that causes them.

\section{THE NEUROPSYCHOLOGY OF HYSTERIA Hysterical paralysis}

The first neuroimaging study was completed using single photon emission computed tomography (SPECT) to assess cerebral perfusion in an individual diagnosed with hysterical anaesthesia and paralysis. ${ }^{8}$ The researchers found decreases in right parietal activity and increases in right frontal activity when the median nerve on the paralysed left side was electrically stimulated with the asymmetry in these two areas largely resolving on recovery. A more detailed study by Vuilleumier and colleagues, ${ }^{9}$ also using SPECT, investigated seven patients with single sided hysterical paralysis and sensorimotor loss. The design involved passive vibratory stimulation of both hands when the deficit was present, and 2-4 months later after recovery. This study found regional cerebral blood flow decreases in the basal ganglia and thalamus contralateral to the paralysis when symptoms were present but not when the condition had resolved. The authors suggested that the hysterical sensorimotor loss symptoms may result from dysfunction in striatothalamocortical circuits controlling sensorimotor and voluntary motor behaviour, and that motor processes may be modulated by inputs from regions such as anterior cingulate cortex (ACC) or the orbitofrontal cortex (OFC) to the basal ganglia and thalamus. In each of these studies, brain activation was compared when the deficit was present, and then later when it had resolved, so regional cerebral blood flow changes could be directly correlated with the presence of hysterical symptoms. Nevertheless, in both cases, although sensory stimulation was provided, patients were entirely passive and the studies did not explore the task related neural basis of alterations in voluntary motor control by requiring subjects to attempt to move the affected limb during paralysis and sensory loss, and after their resolution.

In terms of resting state studies, Yazici and Kostakoglu ${ }^{10}$ imaged five patients with conversion paralysis and found that four out of the five patients had left temporal and one patient had left parietal perfusion decreases. A similar study by Tanaka and colleagues ${ }^{11}$ found a resting state reduction in the activity of frontal motor areas in four cases of conversion paralysis. However, as both studies imaged a rest condition and no stimulus or task was introduced, it is again difficult to draw any conclusions about dynamic (ie, task related) differences in function

Marshall and colleagues ${ }^{12}$ reported the first task based functional imaging study of a patient with a left sided hysterical paralysis using PET. When asked to move the paralysed leg, there was no activation in the contralateral motor cortex and this was accompanied by an activation increase in the right ACC and right OFC. This was not seen when the good leg was moved, which was accompanied by normal contralateral motor cortex activation. This activation task based type of study was later extended by Spence and colleagues ${ }^{13}$ in a small case series that compared patients with hysterical weakness to four participants instructed to feign motor weakness and two normally moving controls. Patients were distinguished by a reduction in left dorsolateral prefrontal cortex (DLPFC) activity regardless of their side of weakness while feigners were distinguished by a reduction in right DLPFC activation.

As outlined in table 1, functional MRI (fMRI) studies on hysterical paralysis typically show functional decreases in brain regions related to the impairment associated with increases in prefrontal cortex activity. This supports the explanation that the impairment is due to inhibition of the primary motor areas by higher level systems at some point during sensory or motor processing. However, a refinement of the executive control explanation presented by Cojan and colleagues $^{20}$ used a GO-NOGO task to examine brain activation during movement preparation, execution and inhibition in a patient with left handed hysterical conversion paralysis in comparison with a group of healthy controls. These authors reported that right motor cortex activity was present during preparation to move (also previously reported in the case study by Marshall and colleagues ${ }^{20}$ ) which argues against the idea that hysterical paralysis functions through an inhibition during motor intention. Notably, conscious inhibition of movement in the NOGO trials in the Cojan et al study ${ }^{20}$ was associated with inferior frontal gyrus activation which was not present in paralysis related movement failure to GO stimuli. Rather, paralysis related response failure was associated with increased activation in the right ventrolateral prefrontal cortex, left superior frontal gyrus and bilateral precuneus. The authors note that the ventrolateral prefrontal cortex receives inputs from executive regions involved in emotion processing such as OFC and ventromedial prefrontal cortex, and may thus act as a point at which affective information can influence task related representations held in prefrontal regions. Further, functional connectivity was increased between the motor cortex and midline cortical regions involved in self-referent processing, including the ventromedial prefrontal cortex (PFC) and precuneus. These authors therefore proposed that hysterical paralysis may occur through the influence of internal representations and memories related to the self affecting the motor execution stage.

Studies using transcranial magnetic stimulation to stimulate the primary motor cortex of patients with hysterical paralysis have found normal motor evoked potentials, in keeping with the proposal that changes in higher level control systems underpin the disorders (eg, see Cantello and colleagues ${ }^{23}$ ). It should be noted, though, that three studies of patients with diagnosed psychogenic dystonia (abnormal muscle tone) reported unusual motor evoked potentials (reviewed in Quartarone and colleagues ${ }^{24}$ ). This may result from an adaptation to the maintenance of chronic abnormal muscle tone which is nonetheless proximally caused by changes in higher level control systems. Alternatively, there may be an as yet unknown impairment in the primary motor pathway associated with this disorder or, possibly, the diagnosis (at least in the patients studied) may be inaccurate.

\section{Functional sensory syndromes}

Numerous studies have shown that evoked potentials measured with both electroencephalography and magnetoencephalography 
Table 1 Summary of SPECT, PET and fMRI studies of motor and sensory hysteria

\begin{tabular}{|c|c|c|c|c|}
\hline Study, participants & Impairment & Method & Critical comparison & Changes during task \\
\hline Tiihonen $1995^{8}$ - Single case & $\mathrm{L}$ paralysis, paresthesia & SPECT & $\begin{array}{l}\text { Affected vs recovered during stimulation } \\
\text { of } L \text { median nerve }\end{array}$ & $\begin{array}{l}\imath \text { Right frontal } \\
\checkmark \text { Right parietal }\end{array}$ \\
\hline Marshall $1997^{12}$ - Single case & $\mathrm{L}$ paralysis & PET & $\begin{array}{l}\text { Motor execution attempt vs motor } \\
\text { preparation }\end{array}$ & $\begin{array}{l}\text { i Right } \mathrm{ACC} \text { and right } \mathrm{OFC} \\
\bigcirc \text { Motor cortex }\end{array}$ \\
\hline $\begin{array}{l}\text { Spence } 2000^{13} \text {-Three patients, four } \\
\text { feigners, two controls }\end{array}$ & Hysterical weakness & PET & Patients vs feigners & $\begin{array}{l}\text { Patients: } \checkmark \text { Left DLPFC } \\
\text { Feigners: } \checkmark \text { Right DLPFC }\end{array}$ \\
\hline Vuilleumier $2001^{9}$-Seven patients & $\begin{array}{l}\text { Subjective paralysis, weakness, } \\
\text { some with sensory loss }\end{array}$ & SPECT & $\begin{array}{l}\text { Affected versus recovered and resting } \\
\text { state vs vibratory stimulus. }\end{array}$ & $\begin{array}{l}\text { ת Contralateral basal ganglia and thalamus } \\
\text { in affected state } \\
\text { il Ipsilateral pre and post central gyrus on } \\
\text { recovery }\end{array}$ \\
\hline Mailis-Gagnon $2003^{14}$-Four patients & $\begin{array}{l}\text { Chronic pain with hysterical } \\
\text { anaesthesia }\end{array}$ & fMRI & $\begin{array}{l}\text { Affected vs unaffected body parts and } \\
\text { mild vs noxious stimulation. }\end{array}$ & $\begin{array}{l}\uparrow A C C \\
\bigcirc \text { Thalamus, insula, inferior frontal, } \\
\text { posterior ACC } \\
\sqrt{\Omega} \text { Contralateral motor cortices, bilateral } \\
\text { prefrontal }\end{array}$ \\
\hline Werring $2004^{15}$-Five patients & Medically unexplained vision loss & fMRI & $8 \mathrm{~Hz}$ visual stimulation vs darkness & $\begin{array}{l}1 \text { Left posterior ACC, left inferior frontal } \\
\text { cortex, left insula-claustrum, bilateral } \\
\text { striatum and thalami, left limbic structures } \\
\text { ป Visual cortex }\end{array}$ \\
\hline Burgmer et al $2006^{16}$-Four patients & Left or right sided hand paralysis & fMRI & $\begin{array}{l}\text { Passive observation of video clip of } \\
\text { moving hand or hand at rest. }\end{array}$ & $\begin{array}{l}\text { ת Cortical hand areas during movement } \\
\text { observation }\end{array}$ \\
\hline Ghaffar $2006^{17}$-Three patients & $\begin{array}{l}\text { Unilateral conversion disorder, } \\
\text { sensory subtype }\end{array}$ & fMRI & $\begin{array}{l}\text { Vibratory stimulation of affected area vs } \\
\text { unaffected area vs bilateral stimulation }\end{array}$ & $\begin{array}{l}\text { ¿ OFC, ACC, secondary somatosensory } \\
\text { cortex, basal ganglia/putamen, thalamus } \\
\text { C Contralateral primary somatosensory } \\
\text { cortex }\end{array}$ \\
\hline $\begin{array}{l}\text { Stone } 2007^{18} \text {-Four patients, four } \\
\text { feigners }\end{array}$ & Unilateral ankle weakness & fMRI & Movement in feigners vs controls & $\begin{array}{l}\text { i Putamen and lingual gyri bilaterally, left } \\
\text { inferior frontal gyrus, left insula } \\
\neg \text { Right middle frontal and OFCs }\end{array}$ \\
\hline de Lange $2007^{19}$-Eight patients & Arm paralysis & fMRI & $\begin{array}{l}\text { Mental rotation of affected vs unaffected } \\
\text { arm }\end{array}$ & $\begin{array}{l}i \text { Medial prefrontal cortex, superior } \\
\text { temporal cortex } \\
\text { No change in motor activation }\end{array}$ \\
\hline Kanaan et al $2007^{5}$ Single case & $\mathrm{R}$ sided paralysis & fMRI & $\begin{array}{l}\text { Recalling traumatic vs non-traumatic } \\
\text { memories }\end{array}$ & $\begin{array}{l}\uparrow \text { Amygdala and right inferior frontal lobe } \\
\curlyvee \text { Motor cortex }\end{array}$ \\
\hline $\begin{array}{l}\text { Cojan } 2009^{20} \text { - Single case, } 30 \text { healthy } \\
\text { controls with feigning condition }\end{array}$ & $\mathrm{L}$ arm weakness & fMRI & $\begin{array}{l}\text { GO-NOGO task: affected left vs right } \\
\text { hand; preparation versus response vs } \\
\text { response inhibition; patient vs controls. }\end{array}$ & $\begin{array}{l}\text { Left hand preparation: } r \text { right motor } \\
\text { cortex, left OFC, right vmPFC and PCC; } \\
\text { left hand response failure: iright ventro- } \\
\text { lateral PFC, left SFG and bilateral precu- } \\
\text { neus }\end{array}$ \\
\hline de Lange $2010^{21}$-Eight patients & $\begin{array}{l}\text { Full or partial right or left arm } \\
\text { paralysis }\end{array}$ & fMRI & $\begin{array}{l}\text { Mental rotation of affected vs unaffected } \\
\text { arm }\end{array}$ & $\begin{array}{l}\text { Connectivity analysis: increased positive } \\
\text { coupling between DLPFC and dorsal } \\
\text { premotor cortex. Increased negative } \\
\text { coupling between DLPFC and dorsal } \\
\text { premotor cortex. }\end{array}$ \\
\hline Voon $2010 a^{22}$-Eight patients & Psychogenic tremor & fMRI & Conversion vs voluntary tremor & $\begin{array}{l}\text { iCerebellar vermis, left sensorimotor } \\
\text { cortex. } \\
\checkmark \text { Right temporoparietal junction } \\
\text { Decrease functional connectivity between } \\
\text { right temporoparietal junction and: bilat- } \\
\text { eral sensorimotor cortices, bilateral cere- } \\
\text { bellar vermis, left ventral striatum, and } \\
\text { bilateral ventral cingulate/medial PFC }\end{array}$ \\
\hline $\begin{array}{l}\text { Voon } 2010 b^{6}-16 \text { patients, } 16 \text { matched } \\
\text { controls }\end{array}$ & $\begin{array}{l}\text { Psychogenic tremor, dystonia } \\
\text { or gait abnormalities }\end{array}$ & fMRI & $\begin{array}{l}\text { Functional connectivity in patients versus } \\
\text { controls during affective stimulation }\end{array}$ & $\begin{array}{l}\text { ORight amygdala to fearful versus } \\
\text { neutral compared with happy vs neutral } \\
\text { faces. } \\
\text { iRight amygdala happy faces } \\
\text { Greater functional connectivity between } \\
\text { the right amygdala and the right supple- } \\
\text { mentary motor }\end{array}$ \\
\hline
\end{tabular}

$\uparrow$, increased activation; $\Omega$, decreased activation; $\bigcirc$, lack of expected activation.

ACC, anterior cingulate cortex; DLPFC, dorsolateral prefrontal cortex; fMRI, functional MRI; OFC, orbitofrontal cortex; PCC, posterior cingulate cortex; PET, positron emission tomography;

PFC, prefrontal cortex; SFG, superior frontal gyrus; SPECT, single photon emission computed tomography; vmPFC, ventromedial prefrontal cortex.

are normal during sensory stimulation ${ }^{25}$ to the point where they are considered diagnostic in hysterical blindness, deafness and anaesthesia. Furthermore, while the signal linked to primary sensory processing is intact, the signals in higher level brain areas associated with cognitive processing have been found to be abnormal compared with normal subjects or those asked to simulate the impairment. ${ }^{25}$ Hence these studies have shown hysterical sensory loss in different modalities (vision, hearing, touch) to be associated with normal early sensory cortical processing.

Nevertheless, an fMRI study by Ghaffar and colleagues ${ }^{17}$ showed that hysterical sensory symptoms can be associated with task related changes in activity in primary sensory cortices as well as in higher level control regions. The study involved three patients, two with hysterical anaesthesia and one with both anaesthesia and paraesthesia (tingling). Vibrotactile stimulation to the affected area was compared with an equivalent unaffected area on the contralateral side, and with bilateral stimulation. Each patient was analysed separately, and in all cases stimulation of the affected region did not result in the expected activation in the contralateral primary somatosensory cortex that occurred when the unaffected region was stimulated. Furthermore, the lack of expected activation was variously accompanied by activation increases in the OFC, ACC, 
secondary somatosensory cortex and basal ganglia. The results from the study of Ghaffar et al suggest an apparent contradiction to the electrophysiological studies that typically show no differences in the responses of primary sensory areas between patients and controls. However, it is not yet clear how closely the measurements reflect similar processing owing to differing methodologies and temporal resolution of the measurements which have been shown previously to produce different results in sensory paradigms.

\section{Functional amnesia}

Dissociative, functional or psychogenic amnesias involve autobiographical memory loss, often for traumatic or stressful events, in the absence of neuropathology that could explain the cognitive impairment. ${ }^{26}$ The disorder is typically characterised by a profound loss of past memories, often associated with 'fugue' states involving loss of identity and wandering (usually in the context of severe precipitating psychosocial stress); depression; and a history of transient organic amnesia. Two main theories have attempted to explain the aetiology and maintenance of the condition: Kopelman ${ }^{26}$ proposes that functional amnesia results from arousal driven prefrontal inhibition of the medial temporal and diencephalon memory retrieval mechanisms, in line with similar theories of dissociative symptoms where top down executive inhibition is postulated. ${ }^{27}$ In contrast, Markowitsch ${ }^{28}$ argues that precipitating events cause the release of stress related hormones resulting in a "mnestic block syndrome' characterised by functional dissociation of fronto-temporal regions, particularly of the right hemisphere where dissociative amnesia is caused by failure to engage the medial temporal/diencephalic system, rather than its active inhibition

As can be seen from table 2, resting state studies using (18F) fluorodeoxyglucose-positron emission tomography (FDG-PET) or SPECT in patients with functional amnesia syndromes have typically found reduced metabolic activity in the right inferolateral PFC, ${ }^{35}$ with fewer studies reporting reduced temporal metabolism $^{30}{ }^{34}$ or perfusion ${ }^{29}$ with varying laterality. By contrast, activation studies in patients with dissociative amnesia more commonly report increased prefrontal and decreased medial temporal/diencephalic activity associated with inability to remember, often alongside other changes in brain activity. Of the six patients included in relevant activation studies reviewed in table 2, three showed greater DLPFC activity and one greater lateral PFC (BA 8) activation in tasks contrasting stimuli from amnesic relative to non-amnesic periods, while four showed reduced medial temporal lobe/diencephalic activations, although with varying laterality, differential activation of subregions and complex patterns of changes where repeated measures were taken.

In terms of theoretical models, resting state studies are generally consistent with Markowitsch's ${ }^{28}$ view that functional amnesia results from failure to cue autobiographical memory retrieval while activation studies are consistent with Kopelman's ${ }^{26}$ executive inhibition model. This apparent contradiction may reflect the operation of both processes in individuals with dissociative amnesia as indicated by two single case studies, one using SPECT and PET $^{3}$ and one using FDG-PET and FMRI. ${ }^{3}$ These studies demonstrated right frontal and temporal hypoperfusion and temporal hypometabolism, respectively, during resting state but increased prefrontal/executive activation during attempted retrieval of information from the amnesic relative to remembered periods.

One possibility is that reduced resting state metabolism or perfusion in right ventral frontal and/or temporal regions reflects basal underactivity in memory systems secondary to chronic executive inhibition. Equally, executive processes could be recruited to inhibit retrieval when the 'mnestic block syndrome' fails to prevent the cueing of memory retrieval. This raises the possibility that executive inhibition may be sufficient to cause functional memory suppression in the absence of high arousal and stress hormone release-for example, in motivated forgetting, suggested amnesia and in culturally influenced forms of circumscribed autobiographical memory loss such as spirit possession

\section{Summary}

Evidence from electroencephalography, transcranial magnetic stimulation and behavioural studies indicate that early processing in primary sensory and motor cortices remains functionally intact in people diagnosed with hysterical sensorimotor syndromes, suggesting that the impairment stems from task related inhibition involving high level processes (eg, suppression of primary motor cortex during paralysis; primary sensory cortex during sensory loss; and by analogy the medial temporal lobe memory system during amnesia). Neuroimaging research has generally supported this model, indicating that the process of dissociation implicated in symptom formation and expression may be mediated by top down inhibition involving areas in the prefrontal cortex. This suggests the likely involvement of executive regions modulating attention, response selection and inhibition-possibly interacting with emotion executive and self-related processing regions-although it is still not clear at what point in the process inhibition occurs and how much variation there might be in the mechanisms that produce similar symptoms. For example, voluntary and involuntary (hysterical) movement inhibition have overlapping but distinct patterns of increased activity in executive systems. ${ }^{20} \mathrm{Also}$, evidence of reduced resting metabolism in executive systems (eg, right inferolateral PFC in patients with dissociative amnesia ${ }^{35}$ ) may indicate that in some cases functional (hysterical) symptoms may partly result from a lack of executive engagement of brain systems supporting a basic function (such as retrieval of memories by the medial temporal lobe memory system), rather than task related inhibition.

\section{THE NEUROPSYCHOLOGY OF HYPNOSIS}

In contrast to hysteria, we can be more confident about the sequence of events, at least in the procedural sense, leading up to the 'end states' associated with hypnosis. The content of the suggestion is key to determining the nature of the 'hypnotic' phenomenon (eg, leg paralysis), which can be described as a form of dissociation (or 'compartmentalisation'). ${ }^{3}$ Although the brain mechanisms underlying this process are still far from clear, it is known from neuroimaging studies that altered patterns of brain activity accompany the focused and absorbed 'hypnotic' state and there is particularly strong evidence that distinct brain changes are associated with each of the hypnotic phenomena so far studied. For general reviews on the neuropsychology of hypnosis and suggestion, see Oakley and Halligan. ${ }^{37}$

\section{NEUROPSYCHOLOGICAL EVIDENCE FOR DISSOCIATION IN HYPNOSIS}

'State' theories of hypnosis (such as Hilgard's 'neodissociation' theory, and Bowers' 'dissociated control' theory) imply that hypnosis per se involves an altered state of consciousness. An alternative approach, enshrined in 'non-state' theories, suggests that hypnosis does not involve a special altered state of 
Table 2 Summary of SPECT, PET and fMRI studies of psychogenic amnesia

\begin{tabular}{llll}
\hline Study, participants & Impairment & Method & Critical comparison \\
\hline Markowitsch $1997^{29}-$ & Probable psychogenic & SPECT (resting & SPECT 3 weeks post onset. PET \\
Single case & amnesia, retrograde & perfusion), & 6 months post onset. Episodic retrieval: \\
& & PET (activation) & $\begin{array}{l}\text { old sentences (information heard one } \\
\text { day prior to scanning) vs new sentences }\end{array}$
\end{tabular}

Markowitsch $2000^{30}$

Single case

Yasuno $2000^{31}$ - Single case, Psychogenic amnesia

12 healthy controls

retrograde
Psychic shock induced mnestic block syndrome

\section{FDG-PET (resting)}

2 vs 12 months after syndrome onset each in comparison with controls, some recovery at 12 month mark. $\mathrm{RO}$ in temporal lobes and thalami only

PET (activation) Interaction: famous face versus gender discrimination, 2 vs 12 months after syndrome onset. No direct statistical comparison with controls.

fMRI

psychogenic amnesia

after a severe stressful event.

Psychogenic autobiographical memory loss for period to age 16

Recognisable faces of pre-amnesic period friends. Unrecognisable faces of postamnesia period friends. Unfamiliar faces. No direct statistical comparison

Recall of residual autobiographical memories from amnesic period vs recall
Botzung $2007^{33}$

Single case
Persistent retrograde amnesia following a dissociative fugue
Hennig-Fast $2008^{34}$

Single case, 9

healthy controls
FDG-PET (resting, acute state only) fMRI versus various types of nonautobiographical information. Acute state vs one year post-onset. No direct statistical analysis of interaction from preserved period (rather than successful inhibition of memories from amnesic period)

FDG-PET (resting)

Dissociative amnesia, with variable antereograde and executive impairments.

Kikuchi $2010^{36}$

Two patients
Dissociative amnesia
'Unrecognised' (but previously known) faces from amnesia period vs recognised faces from remembered period
Changes

Resting SPECT: $\Omega$ right inferior frontal and anterior temporal cortex

PET: îbilateral precuneus and parietal right lateral PFC (BA 8) and PCC.

$\checkmark$ Left middle temporal gyrus and superior temporal gyrus, bilateral premotor cortex, left thalamus and cerebellum

At 2 months: $\preccurlyeq$ left temporal mesial cortex and thalamus.

At 12 months: normalised metabolism

î Left medial frontal cortex and right hippocampal region at 12 relative to 2 months

Left ACC and parieto-occipital junction right occipital cortex, middle lateral PFC (BA 9, DLPFC) and anterior medial temporal region including the amygdala at 12 relative to 2 months

Recognisable faces: ¿ amygdala, hippo-

campus, parahippocampal gyrus and insula.

Unrecognisable and unfamiliar faces: 'significantly less activation in the limbic area'

仓Left superior temporal gyrus, insula, posterior inferior temporal gyrus, precuneus, superior parietal gyrus, cerebellum. Right inferior occipital gyrus, temporooccipital junction, superior parietal gyrus. Bilateral retrosplenial and PCC.

ᄂeft parahippocampal gyrus, ACC, precuneus, DLPC, middle frontal gyrus. Resting PET:

Reduced metabolism right temporomesial area.

fMRI, acute state, autobiographical: id dorsal ACC and PCC, precentral and subcallosal gyrus, medial PFC

Otemporo-occipital cortex

Temporo-occipital activation normalised one year post-onset.

$\checkmark$ Right inferolateral PFC

Left hippocampus in 2 out of 14 patients.

ঊBilateral DLPFC and ventrolateral PFC

そhippocampus

仓, increased activation;, decreased activation; $\bigcirc$, lack of expected activation.

ACC, anterior cingulate cortex; DLPFC, dorsolateral prefrontal cortex; FDG-PET, (18F) fluorodeoxyglucose-positron emission tomography; fMRI, functional MRI; OFC, orbitofrontal cortex

PCC, posterior cingulate cortex; PFC, prefrontal cortex; SFG, superior frontal gyrus; SPECT, single photon emission computed tomography; vmPFC, ventromedial prefrontal cortex.

consciousness as part of its causal mechanism. ${ }^{27}$ While this remains a key debate in hypnosis, it does not directly bear on the issue of dissociation, which in principle could operate with or without an 'altered state'.

Indeed, one approach that is not specifically a 'state theory' but does include a dissociative component has been put forward by Oakley. ${ }^{27}$ This model uses 'state' in a purely descriptive, rather than causal, sense to simply describe subjective changes associated with hypnosis (such as mental absorption and focusing of attention), and draws inspiration from Norman and Shallice's contention scheduling/supervisory attentional model of executive function. In Norman and Shallice's model the supervisory attentional system can intervene in non-routine situations specifically to control or modulate actions by deploying top down attentional resources. Well practised action sequences, however, become automatic and can be triggered by environmental circumstances acting directly on lower level executive structures with little conscious involvement ('contention scheduling'). Against this background, Oakley posits a 'level 1' system of which we have full awareness and involves limited capacity, analytical processing and conscious self-reflection. The 'level 2' system is equivalent to both the supervisory attentional system and contention scheduling system of the Norman and Shallice model, but has the additional role of selecting a subset of currently active representations for processing in the 'level 1' self-awareness system, which may be reflected in conscious thoughts. In this model, 'suggestions' serve to influence processing in the 'level 2' system and include environmental prompts, verbal information from others or our own beliefs, motives and expectancies. This process is facilitated by the focusing of attention, by absorption in internal mental events, and disattention to external stimuli that are typical products of hypnosis induction procedures. Anything which results from influences acting directly on the 'level 2' system is likely to appear to the 'level 1' system as automatic or unintentional. Hence, in this model both hypnotic and hysterical symptoms can be explained, as produced by suggestion driven alterations in activity of the level 2 system, which in turn influences the conscious content of the level 1 system. 
As it is known that individuals differ in their extent of hypnotisability, and that this may reflect intrinsic variations in executive functions, evidence relevant to trait and state differences will be reviewed below.

\section{HYPNOTIC MODELS OF HYSTERIA}

At a purely phenomenological level, hypnosis has long been associated with hysteria ${ }^{1}$ and more recent empirical work has attempted to examine this link in more detail, first by looking at the association between susceptibility to hypnosis and prevalence of hysteria, and second by directly comparing the neuropsychological effects of a hypnotically suggested impairment as a model of an equivalent hysterical symptom.

\section{Trait associations between hysteria and hypnotisability}

Only relatively recently have investigators begun to examine whether trait hypnotisability is related to the clinical presentation of hysteria and related symptoms. Bliss ${ }^{38}$ initially reported high rates of hypnotisability in a group of patients with hysteria compared with controls, and this was subsequently replicated in a larger study by Roelofs et al ${ }^{39} 40$ One study, by Moene and colleagues, ${ }^{41}$ did not find higher levels of hypnotisability in patients although they reported a difference on trait measures of dissociation and found that conversion disorder inpatients were significantly more hypnotisable than similarly diagnosed outpatients.

The association between non-epileptic seizures and hypnotisability is rather more equivocal, however. While Kuyk and colleagues ${ }^{42}$ reported on a group of patients with non-epileptic seizures, finding them significantly more hypnotisable than patients with epilepsy, this has not been replicated by Goldstein and colleagues ${ }^{43}$ and Litwin and Cardeña. ${ }^{44}$

\section{Modelling symptoms with suggestions in highly hypnotisable subjects \\ Hypnotic paralysis}

Building on their earlier task based neuroimaging study of hysterical paralysis, ${ }^{12}$ Halligan and colleagues ${ }^{45}$ replicated the study methodology but used a left leg paralysis suggestion in a single hypnotised participant to produce a functionally identical impairment to the patient in their previous study. The areas of brain activation during attempted movement (increased right ACC cortex and right OFC without motor cortex activation) were close to those of their earlier clinical study. It was concluded that in neurocognitive terms, the mechanisms of hypnotically suggested and hysterical paralysis might be similar and that modelling of hysterical symptoms with suggestions remains an important investigative tool. Aiming to address criticisms that the hypnotised participant might have been faking his paralysis, Ward and colleagues ${ }^{46}$ repeated the study with 12 highly hypnotisable participants who were tested in one part of the study with hypnotically suggested paralysis and in another part were asked, again while hypnotised, to feign the same left leg paralysis in return for a financial reward if they could do so convincingly. While independent clinically trained observers were not able to distinguish hypnotically suggested from feigned paralysis, the hypnotic paralysis condition resulted in brain activation patterns in line with their previous single case study $^{12}$ but markedly different from the feigned condition: specifically, right sided increases were found in the OFC and cerebellum and left sided increases in the thalamus and putamen in hypnotic paralysis compared with increases in the left ventrolateral prefrontal cortex and a number of right posterior cortical structures when faking, although the previously reported activation of the right ACC during hypnotic paralysis was not found.

fMRI studies of hypnotically induced paralysis have also been conducted (noting that the fMRI environment does not interfere with hypnotic modelling of hysterical symptoms). ${ }^{47}$ As a parallel to their neuroimaging study on hysterical conversion paralysis, ${ }^{13}$ Cojan and colleagues ${ }^{48}$ completed an fMRI analogue study, again using the GO-NOGO task with hypnotically induced paralysis. They similarly found normal motor cortex activation during the preparation phase, which was again taken to suggest that movement inhibition was not working through suppression of motor intention. They also reported that anterior prefrontal and ACC activity was increased in all hypnosis conditions, not solely simulated paralysis, suggesting that activity in these areas may be indicative of state related hypnosis changes and do not reflect a specific inhibitory mechanism. As with their study on hysterical paralysis, they found a greater degree of functional connectivity between the motor cortex and precuneus, and similarly argued that motor inhibition may be mediated through imagery based and self-reflective processing rather than direct manipulation of top down executive control.

\section{Hypnotic sensory syndrome analogues}

While imaging studies of hysterical sensory syndromes have largely focused on conditions such as hysterical blindness, deafness and anaesthesia, hypnotic studies have largely focused on analogues of functional pain syndromes (reviewed in Oakley), ${ }^{49}$ with the result that there are few direct comparisons of dissociative sensory symptoms and their hypnotic analogues.

\section{Hypnotic amnesia}

Aiming to simulate psychogenic amnesia, Mendelsohn and colleagues $^{50}$ used hypnosis to impair selectively memory for specific aspects of a film when a post-hypnotic cue was given. The study compared high and low hypnotisable individuals, as well as individuals asked to feign high hypnotisability, and reported that only the high hypnotisable group showed impaired recall and this was associated with reduced activity in the left extrastriate occipital lobe and the left temporal pole, as well as increased activity in the left rostrolateral prefrontal cortex. These effects were reversed when the post-hypnotic amnesia suggestion was reversed. These findings are consistent with studies that demonstrate increased activity in inhibitory regions of the prefrontal cortex and decreased activity in medial temporal lobe regions during attempted recollection of stimuli from amnesic relative to non-amnesic periods in psychogenic amnesia (see table 2).

\section{SUMMARY AND CONCLUSION}

In this review, we have assessed Charcot's hypothesis that similar brain processes underlie the symptoms of hysteria and suggested effects in hypnosis in relation to contemporary research in cognitive neuroscience and neuropsychiatry. The studies above indicate that hypnotisability traits are associated with a tendency to develop dissociative symptoms, at least in the sensorimotor domain; that dissociative symptoms can be modelled with suggestions in highly hypnotisable subjects; and that hypnotic phenomena engage similar brain processes to those underlying hysteria symptoms. One clear theme to emerge from the findings is that 'symptom' activation, whether clinically diagnosed or simulated with hypnosis, is typically associated with increases in prefrontal cortex activity. This suggests 
that intervention by the executive system in both automatic and voluntary cognitive processing is key in both hysteria and hypnosis but several issues remain. One of the most pertinent is deciding by what cognitive and neural mechanisms involuntary inhibition of willed movements take place. Numerous studies have implicated ACC and OFC in the inhibition of movement execution (table 1) whereas the more recent studies of Cojan and colleagues $^{20} 48$ point to the involvement of brain regions involved in affective modulation of motor function (OFC, ventromedial $\mathrm{PFC}$ via the ventrolateral $\mathrm{PFC}$ ), and processing external and internal stimuli relevant to the self (ventromedial PFC and precuneus). This also highlights the issue of the extent to which diverse hysteria-like syndromes share a common neurocognitive basis. For example, while Cojan et al's work ${ }^{20} 48$ focuses on psychogenic paralyses where motor intention is a clearly defined concept, it is less clear that the findings can be as easily applied to hysterical sensory losses, such as psychogenic blindness, where an intention stage is more difficult to conceptualise. One approach to this problem is to employ experimental designs which parcellate phenomena (movement, sensation, memory) into their respective component phases to help identify at what point, and how, hysterical or suggested effects manifest themselves within and between symptom domains (cf. Cojan et al).

It is also not clear what the limits are with respect to the use of hypnosis as a neurocognitive model for learning about the different forms of hysteria. For example, if we assume there is a close correspondence between the genesis of hypnotic and hysterical symptoms, this would imply that in hysteria there is: (a) a focused and absorbed state which in clinical cases may facilitate specific symptomatology; (b) that is followed by acceptance of a some form of (internal or external) suggestion which determines the nature of the 'hysterical' symptom(s) and; (c) the phenomenological experience of a dissociation is accompanied by distinct brain changes associated with the particular symptom. However, the following points are noted.

This account sees hysteria as predominantly an auto-suggestive disorder ${ }^{27}$ whereas in hypnosis the relevant suggestion is traditionally given by another person (hetero-suggestion). However, these are normally initiated intentionally, in contrast with patients with hysterical symptoms who are unaware of, or might be strongly motivated not to acknowledge to themselves or others, any self-suggestions or mental states (such as a focused attentional state, internal imagery or expectancies) that may precede symptom onset. It is notable that Charcot considered the 'idea' influencing hysterical and hypnotic phenomena to be unconscious. In the case of hypnosis, however, usually there is awareness of the imaginal content of the suggestion (except where suggestions of loss of awareness or amnesia for the suggestion are made, as in post-hypnotic suggestion). Nevertheless, there is evidence of different styles of hypnotic responding characterised by differing degrees of automaticity in response generation. Hypnotic subjects with a 'concentrative' response style (who simply focus their attention on the content of suggestions) may experience suggested effects as 'happening by themselves' while those with a 'constructive' response style (who actively 'think with' the suggestion or engage in goal directed imagery) have a greater awareness of active contribution to the suggested effects, even if the resulting symptoms are experienced as involuntary and realistic. ${ }^{27}$ It is not known whether, or to what extent, patients with hysteria display analogues of 'concentrative' and 'constructive' response styles to generate symptoms-and researching this would be difficult because of the interest of patients with hysteria to avoid acknowledging psychological processes that cause or maintain their symptoms. Furthermore, most hysteria symptoms, unlike hypnotic phenomena, are chronic and are not easily terminated or modified by external suggestion. One possibility is that the resistance of these symptoms to change may be because the 'suggestion' that created them is implicit and reinforced internally (Charcot's 'idea') based on a psychologically relevant need, belief or formative experience. While this has been one of the most popular historical explanations for the aetiology of hysteria (and indeed, still forms the basis of the 'psychological factor' required in the DSM-IV diagnosis), the theory remains largely unspecified.

While the recent literature has provided some compelling leads into the understanding of these phenomena, it is apparent that the field still lacks the well controlled systematically designed studies that could give a clear insight into the neurocognitive processes behind dissociation in both hysteria and hypnosis. We hope this review provides a stimulus for this effort and raises some useful questions to focus future research.

Funding The authors gratefully acknowledge the role of The Psychiatry Research Trust in funding research which has facilitated the writing of this review article.

Competing interests None.

Provenance and peer review Commissioned; externally peer reviewed.

\section{REFERENCES}

1. Ellenberger $\mathbf{H}$. The discovery of the unconscious: the history and evolution of dynamic psychiatry. New York: Basic Books, 1970.

2. Kirsch I. Changing expectations: a key to effective psychotherapy. California: Brooks, 1990:171.

3. Brown RJ. Psychological mechanisms of medically unexplained symptoms: an integrative conceptual model. Psychol Bull 2004;130:793-812.

4. Crimlisk HL, Bhatia K, Cope $H$, et al. Slater revisited: 6 year follow up study of patients with medically unexplained motor symptoms. BMJ 1998:316:582-6.

5. Kanaan RA, Craig TK, Wessely SC, et al. Imaging repressed memories in motor conversion disorder. Psychosom Med 2007;69:202-5.

6. Voon V, Brezing C, Gallea $C$, et al. Emotional stimuli and motor conversion disorder. Brain 2010;133:1526-36

7. Holmes EA, Brown RJ, Mansell W, et al. Are there two qualitatively distinct forms of dissociation? A review and some clinical implications. Clin Psychol Rev 2005;25:1-23

8. Tiihonen J, Kuikka J, Viinamaki H, et al. Altered cerebral blood flow during hysterical paraesthesia. Biol Psychiatry 1995;37:134-5.

9. Vuilleumier $\mathbf{P}$, Chicherio $C$, Assal F, et al. Functional neuroanatomical correlates of hysterical sensorimotor loss. Brain 2001:124:1077-90.

10. Yazici KM, Kostakoglu L. Cerebral blood flow changes in patients with conversion disorder. Psychiatry Res 1998;83:163-8.

11. Tanaka Y, Albert ML, Miyazaki M, et al. Pseudohysterical hemiparesis. J Nerv Ment Dis 2007;195:874-6.

12. Marshall JC, Halligan PW, Fink GR, et al. The functional anatomy of a hysterical paralysis. Cognition 1997:64:B1-8.

13. Spence SA, Crimlisk HL, Cope H, et al. Discrete neurophysiological correlates in prefrontal cortex during hysterical and feigned disorder of movement. Lancet 2000;355:1243-4.

14. Mailis-Gagnon A, Giannoylis I, Downar J, et al. Altered central somatosensory processing in chronic pain patients with 'hysterical' anesthesia. Neurology 2003;60:1501-7

15. Werring DJ, Weston L, Bullmore ET, et al. Functional magnetic resonance imaging of the cerebral response to visual stimulation in medically unexplained visual loss. Psychol Med 2004;34:583-9.

16. Burgmer $\mathbf{M}$, Konrad $\mathbf{C}$, Jansen $\mathbf{A}$, et al. Abnormal brain activation during movement observation in patients with conversion paralysis. Neuroimage 2006;29:1336-43.

17. Ghaffar $\mathbf{0}$, Staines WR, Feinstein A. Unexplained neurologic symptoms: an fMRI study of sensory conversion disorder. Neurology 2006;67:2036-8.

18. Stone J, Zeman A, Simonotto E, et al. fMRI in patients with motor conversion symptoms and controls with simulated weakness. Psychosom Med 2007:69:961-9.

19. de Lange FP, Roelofs K, Toni I. Increased self-monitoring during imagined movements in conversion paralysis. Neuropsychologia 2007:45:2051-8.

20. Cojan Y, Waber L, Carruzzo A, et al. Motor inhibition in hysterical conversion paralysis. Neuroimage 2009;47:1026-37.

21. de Lange FP, Toni I, Roelofs K. Altered connectivity between prefrontal and sensorimotor cortex in conversion paralysis. Neuropsychologia 2010;48:1782-8. 
22. Voon V, Gallea C, Hattori N, et al. The involuntary nature of conversion disorder. Neurology 2010;74:223-8.

23. Cantello R, Boccagni $\mathrm{C}$, Comi $\mathrm{C}$, et al. Diagnosis of psychogenic paralysis: the role of motor evoked potentials. J Neurol 2001;248:889-97.

24. Quartarone A, Rizzo V, Terranova C, et al. Abnormal sensorimotor plasticity in organic but not in psychogenic dystonia. Brain 2009;132:2871-7.

25. Black DN, Seritan AL, Taber KH, et al. Conversion hysteria: lessons from functional imaging. J Neuropsychiatry Clin Neurosci 2004;16:245-51.

26. Kopelman MD. Disorders of memory. Brain 2002;125:2152-90.

27. Oakley DA. Hypnosis and conversion hysteria: a unifying model. Cognit Neuropsychiatry 1999:4:243-65.

28. Markowitsch HJ. Psychogenic amnesia. Neuroimage 2003;20(Suppl 1):S132-8

29. Markowitsch HJ, Calabrese P, Fink GR, et al. Impaired episodic memory retrieval in a case of probable psychogenic amnesia. Psychiatry Res 1997;74:119-26.

30. Markowitsch HJ, Kessler J, Weber-Luxenburger G, et al. Neuroimaging and behavioral correlates of recovery from mnestic block syndrome and other cognitive deteriorations. Neuropsychiatry Neuropsychol Behav Neurol 2000:13:60-6.

31. Yasuno F, Nishikawa T, Nakagawa $Y$, et al. Functional anatomical study of psychogenic amnesia. Psychiatry Res 2000;99:43-57.

32. Yang JC, Jeong GW, Lee MS, et al. Functional MR imaging of psychogenic amnesia: a case report. Korean J Radiol 2005;6:196-9.

33. Botzung A, Denkova E, Manning L. Psychogenic memory deficits associated with functional cerebral changes: an FMRI study. Neurocase 2007:13:378-84.

34. Hennig-Fast K, Meister F, Frodl T, et al. A case of persistent retrograde amnesia following a dissociative fugue: neuropsychological and neurofunctional underpinnings of loss of autobiographical memory and self-awareness. Neuropsychologia 2008;46:2993-3005

35. Brand $\mathbf{M}$, Eggers $\mathbf{C}$, Reinhold N, et al. Functional brain imaging in 14 patients with dissociative amnesia reveals right inferolateral prefrontal hypometabolism. Psychiatry Res 2009;174:32-9.

36. Kikuchi H, Fujii $\mathrm{T}$, Abe $\mathrm{N}$, et al. Memory repression: brain mechanisms underlying dissociative amnesia. J Cogn Neurosci 2010;22:602-13.

37. Oakley DA, Halligan PW. Hypnotic suggestion and cognitive neuroscience. Trends Cogn Sci 2009;13:264-70.
38. Bliss EL. Hysteria and hypnosis J Nerv Ment Dis 1984:172:203-6.

39. Roelofs K, Hoogduin KA, Keijsers GP, et al. Hypnotic susceptibility in patients with conversion disorder. J Abnorm Psychol 2002:111:390-5.

40. Roelofs K, Keijsers GP, Hoogduin KA, et al. Childhood abuse in patients with conversion disorder. Am J Psychiatry 2002;159:1908-13.

41. Moene FC, Spinhoven P, Hoogduin K, et al. Hypnotizability, dissociation and trauma in patients with a conversion disorder: an exploratory study. Clin Psychol Psychother 2001:8:400-10.

42. Kuyk J, Spinhoven P, van Dyck R. Hypnotic recall: a positive criterion in the differential diagnosis between epileptic and pseudoepileptic seizures. Epilepsia 1999:40:485-91.

43. Goldstein LH, Drew C, Mellers J, et al. Dissociation, hypnotizability, coping styles and health locus of control: characteristics of pseudoseizure patients. Seizure 2000:9:314-22.

44. Litwin R, Cardeña E. Demographic and seizure variables, but not hypnotizability or dissociation, differentiated psychogenic from organic seizures. J Trauma Dissociation 2001:1:99-122.

45. Halligan PW, Athwal BS, Oakley DA, et al. Imaging hypnotic paralysis: implications for conversion hysteria. Lancet 2000;355:986-7.

46. Ward NS, Oakley DA, Frackowiak RS, et al. Differential brain activations during intentionally simulated and subjectively experienced paralysis. Cognit Neuropsychiatry 2003:8:295-312

47. Oakley DA, Deeley Q, Halligan PW. Hypnotic depth and response to suggestion under standardized conditions and during FMRI scanning. Int J Clin Exp Hypn 2007:55:32-58.

48. Cojan Y, Waber L, Schwartz S, et al. The brain under self-control: modulation of inhibitory and monitoring cortical networks during hypnotic paralysis. Neuron 2009:62:862-75

49. Oakley DA. Hypnosis, trance and suggestion: evidence from neuroimaging. In: Naish MR, Barnier AJ, eds. The Oxford handbook of hypnosis: theory, research and practice. Oxford: Oxford University Press 2008:365-92.

50. Mendelsohn A, Chalamish Y, Solomonovich A, et al. Mesmerizing memories: brain substrates of episodic memory suppression in posthypnotic amnesia. Neuron 2008:57:159-70. 